\title{
IN VITRO FREE RADICAL SCAVENGING ACTIVITY OF ARISTOLOCHIA TAGALA
}

\author{
KHETBADEI LYSINIA HYNNIEWTA HADEM* , ARNAB SEN \\ Division of Animal Health, Indian Council of Agricultural Research, North-East Headquarter Region Umiam 793103, Meghalaya, India \\ Email: khet21@gmail.com
}

Received: 20 Apr 2018, Revised and Accepted: 10 Jun 2018

\begin{abstract}
Objective: Study of antioxidant activity of a crude aqueous-methanol extract of Aristolochia tagala and its fractions and identification of the compounds with antioxidant activity.
\end{abstract}

Methods: The antioxidant activity was assayed by the ability to scavenge free radicals such as superoxide, nitric oxide and ABTS radical cation and the identification of compounds was carried out by LC/MS analysis.

Results: Fraction I of Aristolochia tagala showed the highest free radical scavenging activity and compounds responsible for its activity were identified as magnoflorine, apigenin dimethyl ether, aristolone, and N-trans-feruloyldopamine.

Conclusion: The free radical scavenging property of the compounds present in Aristolochia tagala may be one mechanism that contributed to medicinal property exhibited by this plant.

Keywords: Aristolochia tagala, Oxidative stress, Antioxidant activity

(C) 2018 The Authors. Published by Innovare Academic Sciences Pvt Ltd. This is an open access article under the CC BY license (http://creativecommons.org/licenses/by/4.0/)

DOI: http://dx.doi.org/10.22159/ijcpr.2018v10i4.28459

\section{INTRODUCTION}

Free radicals are generated within the cells through the metabolic process and they are important for certain cellular responses at low or moderate concentrations. The increase in the concentration of these free radicals can happen when there is an imbalance between their overproduction and the deficiency in free radicals scavenging enzymes and molecules [1]. Exposure to external stress (toxins, radiation, carcinogens) can also lead to the accumulation of free radicals [2-5]. Excessive concentrations of these radicals lead to a situation called as "oxidative stress" and "nitrosative stress" whereby these radicals interact with bio-molecules such as DNA, proteins and lipids and inhibit their normal functions [1]. Oxidative stress and nitrosative stress thus leads to the implications of various diseases such as cancer, diabetes, cardiovascular diseases, neurodegenerative disorders etc. [6-10]. To counter the effects of free radicals damage, it is required to bring the free radicals within normal levels. Several studies have shown the positive effects of antioxidant on ameliorating diseases like cancer, diabetes, alzhimer etc. $[11,12]$. Synthetic antioxidants such as butylated hydroxyltoluene and butylated hydroxyanisole have been commonly used to maintain the quality of ready-to-eat food products, natural antioxidants, however, were found to have higher antioxidant activity when compared with the synthetic ones [13]. Plant-derived antioxidants are of interest due to their potent preventive, as well as therapeutic actions [14]. In this study, the antioxidant activity of Aristolochia tagala which have been reported to have various biological properties was evaluated and LC/MS analysis of compounds present in the fraction with highest antioxidant activity was carried out.

\section{MATERIALS AND METHODS}

Preparation and fractionation of Aristolochia tagala aqueousmethanol extract

Crude aqueous-methanol extract 4:1 (v/v) methanol: water $(100 \mathrm{~g}$ in $250 \mathrm{ml}$ ) was prepared from powdered dried roots of $A$. tagala. The crude extract was designated as ATC. Fractionation of ATC was carried out by open column chromatography in silica gel (100-200 mesh). The extract were eluted out with gradients of $\mathrm{CHCl}_{3}: \mathrm{CH}_{3} \mathrm{OH}$, $100 \mathrm{ml}$ of $95: 5$ and $50 \mathrm{ml}$ of $90: 10,80: 20,70: 30,60: 40,50: 50,40: 60$, $30: 70,20: 80,10: 90$ and $0: 10$. Various fractions of $15 \mathrm{ml}$ each were collected in a clean test tube. Ultraviolet (UV)-visible spectra of individual fractions were recorded and the fractions were combined based on their $\lambda \max$ [15]. They were then dried to completely remove the solvents and varying concentration of ATC and fractions were prepared in methanol and assayed for their antioxidant activity.

\section{Antioxidant properties of ATC and fractions}

The antioxidant properties of ATC and fractions were assayed by their ability to scavenge free radicals like ABTS (2,2-azinobis (3ethyl benzothiazoline)-6-sulfonic acid), superoxide $\left(\mathrm{O}_{2}^{--}\right)$and nitric oxide (NO). The free radical scavenging activities were assayed according to the following protocol.

\section{Nitric oxide radical scavenging}

Nitric oxide generated from aqueous sodium nitroprusside (SNP) was quantified by the Griess Illosvoy reaction [16]. The reaction mixture contained $10 \mathrm{mmol}$ SNP, phosphate buffered saline (pH7.4) and varying concentrations of the samples in 96 well plate. After incubation for $150 \mathrm{~min}$ at $25^{\circ} \mathrm{C}$, Griess reagent $(1 \% \mathrm{w} / \mathrm{v}$ sulphanilamide, $0.1 \% \mathrm{w} / \mathrm{v}$ naphthyl ethylenediamine dihydrochloride in $25 \%$ phosphoric acid) was added and the mixture was incubated for 30 min at $25^{\circ} \mathrm{C}$. The pink chromophore generated was measured at 546 nm against a blank sample.

\section{Superoxide radical scavenging}

Superoxide radical scavenging activity was measured by the reduction of NBT. The reaction mixture contained phosphate buffer $(100$ mmol, pH 7.4), NADH $(73 \mu \mathrm{M})$, NBT $(156 \mu \mathrm{M})$, PMS $(60 \mu \mathrm{M})$ and varying concentrations of the sample solution in a 96 well plate. After incubation for $5 \mathrm{~min}$ at room temperature (r.t), the absorbance at $560 \mathrm{~nm}$ was measured against an appropriate blank to determine the quantity of formazan generated [17].

\section{ABTS scavenging activity}

The total antioxidant activity of the samples was measured by ABTS radical cation decolourization assay according to the method of Re $e t$ al. [18]. ABTS radical cation (ABTS*+) was produced by reacting ABTS stock solution $(1.1 \mathrm{mg} / \mathrm{ml})$ with $2.45 \mathrm{mmol}$ potassium persulfate (final concentration), the mixture was allowed to stand in the dark at room temperature for $6 \mathrm{~h}$ before use. $150 \mu \mathrm{l}$ of the 
ABTS*+ solution was added to $100 \mu \mathrm{l}$ of samples at varying concentrations in a 96 well plate. The absorbance was measured immediately after $5 \mathrm{~min}$ at $734 \mathrm{~nm}$.

\section{Mass spectrometric analysis of the fraction of $\boldsymbol{A}$. tagala}

LC/MS was carried out in XEVO-TQD coupled with Waters Alliance 2695 HPLC system (Waters, USA). Fraction I (1 mg/ml) was prepared in methanol and filtered through a $0.22-\mu \mathrm{m}$ PVDF membrane. C18 SUNFIRE column (250 $\mathrm{mm} \times 4.6 \mathrm{~mm}, 5 \mu \mathrm{m})$ (Waters, USA) was used for LC analyses, the column temperature was set at $30{ }^{\circ} \mathrm{C}$. $20 \mu \mathrm{l}$ of sample was injected automatically by Waters Alliance 2695 autosampler. The mobile phase consists of acetonitrile (A) and $5 \mathrm{mmol}$ ammonium acetate buffer (B). The gradient programme was $95 \%$ B for $0-6 \mathrm{~min}, 70 \% \mathrm{~B}$ for $6-12$ $\min , 40 \%$ for $12-16 \mathrm{~min}, 40 \%$ for $16-20 \mathrm{~min}, 20 \%$ for $20-24,20$ $\%$ for 24-26 min, and $95 \%$ for 26-30 min. Electron Spray Ionisation (ESI) analysis was carried out in XEVO-TQD. The desolvation and cone gas flow were at $950 \mathrm{~L} / \mathrm{h}$ and $30 \mathrm{~L} / \mathrm{h}$ respectively, capillary voltage $3500 \mathrm{~V}$, cone voltage $30 \mathrm{~V}$, source temperature $125^{\circ} \mathrm{C}$, desolvation temperature $350{ }^{\circ} \mathrm{C}$. Collision energy for MS/MS analysis was $10 \mathrm{eV}$. The range for the full ESI scan was set from 150 to 1000 in $\mathrm{m} / \mathrm{z}$. Data acquisition and processing were carried out using MassLynx V4.1 SCN 714 software [19].

\section{Data and statistical analysis}

Statistical analysis was performed by GraphPad Prism 5 Software (GraphPad Software, Inc., USA) using one-way anova followed by Tukey's multiple comparisons test. Data are presented as mean \pm standard deviation. Significance was set at $\mathrm{P}<0.05$.

\section{RESULTS}

Fractionation of the aqueous-methanol extract of roots of Aristolochia tagala yielded thirty-eight fractions which were pooled into four fractions (I-IV) as previously reported [15]. To assess the free radical scavenging potential of ATC and the fractions, the reactivity toward nitric oxide radical (NO), superoxide radical $\left(\mathrm{O}_{2} .^{-}\right)$ and free radical $\mathrm{ABTS}^{\bullet+}$ was measured. The absorbance was converted into an $\mathrm{AA} \%$ which was calculated using the formula $\mathrm{AA} \%$ $\left.=\left[\mathrm{Abs}_{\text {control }}-\left(\mathrm{Abs}_{\text {sample }}-\mathrm{Abs}_{\text {blank }}\right) / \mathrm{Abs}_{\text {control }}\right) \times 100\right]$.

The results are expressed as $\mathrm{IC}_{50}$ value which is the concentration of extract that was able to scavenge $50 \%$ of the free radical. A lower IC $_{50}$ value corresponds to a high antioxidant property and vice versa.

Table 1: $\mathrm{IC}_{50}(\mu \mathrm{g} / \mu \mathrm{l})$ of crude extract or fractions of $A$. tagala $\left({ }^{* * *} \mathrm{P}<0.001,{ }^{* *} \mathrm{P}<0.01, * \mathrm{P}<0.05\right)$

\begin{tabular}{lllll}
\hline & F I & F II & F III & F IV \\
\hline NO. & $102 \pm 0.189^{* * *}$ & $122 \pm 1.599^{* * *}$ & $172 \pm 0.022^{* * *}$ & $135 \pm 0.4544^{* * *}$ \\
$\mathrm{O}_{2}{ }^{-}$ & $152 \pm 0.572^{* * *}$ & $162 \pm 0.150^{* * *}$ & $166 \pm 1.054^{* *}$ & $200 \pm 0.761^{* * *}$ \\
ABTS $^{*+}$ & $850 \pm 0.226^{* * *}$ & $1195 \pm 0.312^{* * *}$ & $1240 \pm 0.031^{* * *}$ & $117 \pm 0.515^{* * *}$ \\
\hline
\end{tabular}

The fractions of $A$. tagala were able to scavenge free radical generated more readily than the crude extract (ATC). The scavenging effect was more prominent for NO radical and ABTS. Fraction I (F I) showed the highest scavenging activity with an IC $_{50}$ value of $102 \mu \mathrm{g} / \mathrm{ml}, 152$ $\mu \mathrm{g} / \mathrm{ml}, 850 \mu \mathrm{g} / \mathrm{ml}$ for $\mathrm{NO}, \mathrm{O}_{2}$-and ABTS respectively (table 1 ).

The total ion chromatogram obtained from LC/MS analysis of F I showed the presence of several compounds (fig. 1). The compound with highest relative abundance was at a retention time (RT) of $24.05 \mathrm{~min}$ in the ESI+mode and $23.85 \mathrm{~min}$ in the ESI-mode. The compound at RT of 24.05 min showed formation of $[\mathrm{M}+\mathrm{H}]^{+}$at $\mathrm{m} / \mathrm{z}$ 343.4 , adduct ion formation $[\mathrm{M}+\mathrm{Na}]^{+}$at $\mathrm{m} / \mathrm{z} \quad 365.4$ and dimer formation $[2 \mathrm{M}+\mathrm{H}]^{+}$at 687.7 and $[2 \mathrm{M}+\mathrm{Na}]^{+}$at $\mathrm{m} / z$ 707.7. The compound at RT 23.85 min showed [M-H]-at $m / z 325.3$ (table 2). These compounds were tentatively identified as magnoflorine and aristolide $C$ respectively based on literature reports of compounds present in $A$. tagala and related species of the same genus and compared to compounds listed in databases Knapsack (http://kanaya.naist.jp) and CHEMnet BASE-Dictionary of Natural Products (http://dnp.chemnetbase.com).
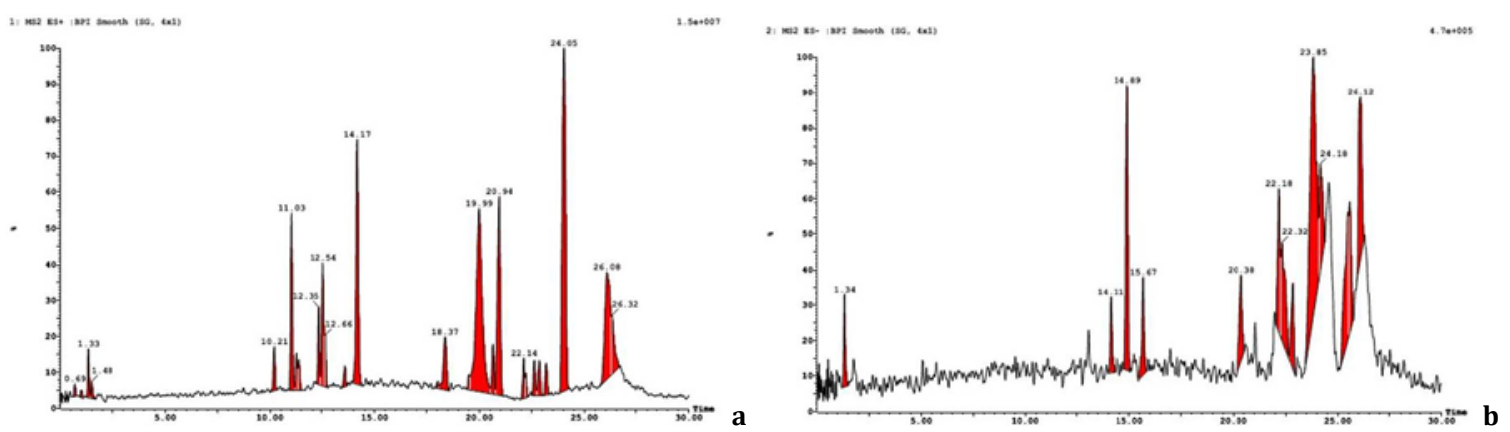

Fig. 1: Total ion chromatogram (TIC) of fraction I of Aristolochia tagala (a) ESI+mode and (b) ESI-mode

Table 2: Compounds present in Fraction I of Aristolochia tagala

\begin{tabular}{|c|c|c|c|c|c|}
\hline \multirow{2}{*}{ S. No. } & \multirow[t]{2}{*}{ RT } & \multirow[t]{2}{*}{ \%RA } & \multicolumn{2}{|l|}{$m / z$} & \multirow{2}{*}{ Compound name } \\
\hline & & & {$[\mathrm{M}+\mathrm{H}]^{+}$} & {$[\mathrm{M}-\mathrm{H}]$} & \\
\hline 1 & 12.35 & 30 & 330.5 & & N-Trans-Feruloyldopamine \\
\hline 2 & 12.54 & 40 & 239.3 & & Aromadendrene $4 \beta, 10 \beta$-diol \\
\hline 3 & 14.17 & 75 & 372.5 & & Aristolochic acid IV \\
\hline 4 & 14.89 & 92 & & 326.2 & Aristolochic acid Ia \\
\hline 5 & 19.99 & 55 & 372.5 & & 7 methoxy aristolochic acid a \\
\hline 6 & 20.94 & 60 & 219.3 & & 3-0xoishwarane \\
\hline 7 & 23.85 & 100 & & 325.3 & Aristolide C \\
\hline 8 & 24.05 & 100 & 343.4 & & Magnoflorine \\
\hline 9 & 24.18 & 70 & & 339.4 & Aristofolin C \\
\hline 10 & 25.48 & 60 & & 297.3 & Apigenin dimethyl ether \\
\hline 11 & 26.12 & 90 & 159 & 217.1 & Aristolone \\
\hline
\end{tabular}




\section{DISCUSSION}

Natural antioxidants are present in a wide variety of food and medicinal plants and they have been reported to have a wide range of biochemical activities, including inhibition of ROS generation, direct or indirect scavenging of free radicals, and alteration of intracellular redox potential $[20,21]$. The in vitro antioxidant activities studies can be used to confer the antioxidant potential of medicinal plants which in turn can give an insight into the role and mechanism of plants in alleviating pathophysiological diseases caused by oxidative stress. Different groups of phytochemicals contribute to the antioxidant activity of plants. Phenolic antioxidants have shown to have excellent antioxidant activity, while other groups of phytochemicals like terpenoids, alkaloids have shown to have moderate antioxidant activity [20]. The antioxidant activity exhibited by Fraction I of $A$. tagala was due to the present of compounds like magnoflorine which was reported to have antioxidant activity both in vitro and in vivo system and was also reported to have anti-inflammatory activity [22-24], apigenin dimethyl ether; reported to have potential antidiabetic and antiobesity properties [23, 25], Aristolone, N-Trans-Feruloyldopamine previously reported to have antioxidant activity $[26,27]$. Aristolochia tagla have been reported to exhibit potential anticancer activity, anti-inflammatory activity, antimicrobial activity [15, 28-30]. The medicinal property exhibited by A. tagala may be contributed by the antioxidants present in this plant which may have helped in reducing the oxidative stress through the scavenging of free radicals generated by exogenous stimuli under different experimental conditions. A. tagala therefore is a good source for extraction of these compounds which shows antioxidant property as well as pathophysiological activity.

\section{ACKNOWLEDGEMENT}

The authors acknowledge the University Grants Commission, Government of India, Sophisticated Analytical Instrument FacilityCentral Drug Research Institute, Lucknow, for LC-MS/MS analysis.

\section{AUTHORS CONTRIBUTIONS}

All the author have contributed equally

\section{CONFLICTS OF INTERESTS}

The authors have no conflict of interest to declare

\section{REFERENCES}

1. Valko M, Leibfritz D, M Jan, Cronin MTD, Mazur M, Telser J. Free radicals and antioxidants in normal physiological functions and human disease. Int J Biochem Cell Biol 2007;39:44-84.

2. Szumiel I. Ionizing radiation-induced oxidative stress, epigenetic changes and genomic instability: the pivotal role of mitochondria. Int J Radiat Biol 2014;91 Suppl 1:1-12.

3. Kakehashi A, Wei M, Fukushima S, Wanibuchi H. Oxidative stress in the carcinogenicity of chemical carcinogens. Cancers 2013;5:1332-54.

4. Ercal N, Gurer-Orhan H, Aykin-Burns N. Toxic metals and oxidative stress part 1:mechanism involved in metal-induced oxidative damage. Curr Top Med Chem 2001;1 Suppl 6:529-39.

5. Omar HEM. Mycotoxins-induced oxidative stress and disease. Available from: http://dx.doi.org/10.5772/51806. [Last accessed on 10 Mar 2018]

6. Noda N, Wakasugi H. Cancer and oxidative stress. Asian Med J 2001;44 Suppl 12:1571-4.

7. Fuchs Tarlovsky V. Role of antioxidants in cancer therapy. Nutrition 2013;29:15-21.

8. Ullah A, Khan A, Khan I. Diabetes mellitus and oxidative stressa concise review. Saudi Pharm J 2016;24:547-53.

9. Gracia KC, Llanas-Cornejo D, Husi H. CVD and oxidative stress. J Clin Med 2017;6 Suppl 2:22.
10. Kim GH, Kim JE, Rhie SJ, Yoon S. The role of oxidative stress in neurodegenerative diseases. Exp Neurobiol 2015;24 Suppl 4:325-40.

11. Li S, Chen G, Zhang C, Wu M, Wu S, Liu Q. Research progress of natural antioxidants in foods for the treatment of diseases. Food Sci Human Wellness 2014;3:110-6.

12. Pham-Huy LA, He H, Pham-Huy C. Free radicals, antioxidants in disease and health. Int J Biomed Sci 2008;4 Suppl 2:89-96.

13. Brewer MS. Natural antioxidants: sources, compounds, mechanisms of action, and potential applications. Compr Rev Food Sci Food Saf 2011;10:221-7.

14. Sati SC, Sati N, Rawat U, Sati OP. Medicinal plants as a source of antioxidants. Res J Phytochem 2010;4 Suppl 4:213-34.

15. Hadem KLH, Sharan RN, Kma L. Phytochemicals of Aristolochia tagala and Curcuma caesia exert an anticancer effect by tumor necrosis factor- $\alpha$-mediated decrease in nuclear factor kappa B binding activity. J Basic Clin Pharma 2016;7:1-11.

16. Sreejayan S, Rao MNA. Nitric oxide scavenging by curcuminoids. J Pharm Pharmacol 1997;49:105-7.

17. Syiem D, Sharma R, Saio V. In vitro antioxidant potential of some traditionally used medicinal plants of North-east India and assessment of their total phenolic content. Pharmacologyonline 2009;3:952-65.

18. Re R, Pellegrini N, Proteggente A, Pannala A, Yang M, Evans CR. Antioxidant activity applying an improved ABTS radical cation decolourization assay. Free Radical Biol Med 1999;26:1231-7.

19. Basaiyye SS, Naoghare PK, Kanojiya S, Bafana A, Arrigo P, Krishnamurthi $\mathrm{K}$, et al. Molecular mechanism of apoptosis induction in Jurkat E6-1 cells by Tribulus terrestris alkaloids extract. J Tradit Complement Med 2017;1-10. https://doi.org/10.1016/j.jtcme.2017.08.014

20. Kasote DM, Katyare SS, Hegde MV, Bae H. Significance of antioxidant potential of plants and its relevance to therapeutic applications. Int J Biol Sci 2015;11 Suppl 8:982-91.

21. Young IS, Woodside JV. Antioxidants in health and disease. J Clin Pathol 2001;54:176-86.

22. Li C, Wang MH. Potential biological activities of Magnoflorine: a compound from Aristolochia debilis Sieb. et Zucc. Korean J Plant Res 2014;27 Suppl 3:223-8.

23. Zulkefli HN, Mohamad J, Abidin NZ. Antioxidant activity of methanol extract of Tinospora crispa and Tabernaemontana corymbosa. Sains Malays 2013;42 Suppl 6:697-706.

24. Hung TM, Lee JP, Min BS, Choi JS, Min KNA, Zhang XF, et al. Magnoflorine from Coptidis rhizoma protects high-density lipoprotein during oxidant stress. Biol Pharm Bull 2007;30 Suppl 6:1157-60.

25. Krishna MS, Joy B, Sundaresan A. Effect on oxidative stress, glucose uptake level and lipid droplet content by Apigenin 7, 4'dimethyl ether isolated from Piper longum L. J Food Sci Technol 2015;52 Suppl 6:3561-70.

26. Wang J, Zhao J, Liu H, Zhou L, Liu Z, Wang J, et al. Chemical analysis and biological activity of the essential oils of two valerianaceous species from China: Nardostachys chinensis and Valeriana officinalis. Molecules 2010;15:6411-22.

27. Dizdar M, Vidic D, Pozgan F, Stefane B, Maksimovi'c M Acetylcholinesterase inhibition and antioxidant activity of $\mathrm{N}$ trans-Caffeoyldopamine and $N$-trans-Feruloyldopamine. Sci Pharm 2018;86:11.

28. Hadem KLH, Sharan RN, Kma L. Inhibitory potential of methanolic extracts of Aristolochia tagala and Curcuma caesia on hepatocellular carcinoma induced by diethylnitrosamine in BALB/c mice. J Carcinog 2014;13:7.

29. Anilkumar ES, Mathew D, Nishanth Kumar S, Dileep Kumar BS, Latha PG. A comparative study on in vitro antioxidant, anticancer and antimicrobial activity of the methanol extracts of the roots of four species of Aristolochia L. from southern Western Ghats of India. Int J Adv Res 2014;2 Suppl 12:153-64.

30. Battu GR, Parimi R, Shekar KBC. In vivo and in vitro pharmacological activity of Aristolochia tagala (syn: Aristolochia acuminata) root extracts. Pharm Biol 2011;49 Suppl 11:1210-4. 